\title{
The Relationship between LBOs, IPOs and Market Risk Premium: An Empirical Analysis of the European Market
}

\author{
Antonio Salvi ${ }^{1}$, Emanuele Teti $^{2} \&$ Anastasia Giakoumelou ${ }^{1}$ \\ ${ }^{1}$ Università LUM Jean Monnet, Italy \\ ${ }^{2}$ Università di Pisa, Italy \\ Correspondence: Emanuele Teti, Università di Pisa, Italy. E-mail: emanuele.teti@unipi.it
}

Received: May 4, 2019

Accepted: May 25, 2019

Online Published: June 15, 2019

doi:10.5539/ijbm.v14n7p160

URL: https://doi.org/10.5539/ijbm.v14n7p160

\begin{abstract}
This paper investigates the relationship between leveraged buyouts (LBOs) and initial public offerings (IPOs) with the market risk premium in the European market. We expand our study to the period spanning from the first quarter of 1999 to the fourth quarter of 2016. Our longitudinal analysis finds evidence of an inverse relationship between market risk premium and the volume of LBOs, as well as a direct relationship between the latter and the stock index STOXX Europe 600. Additionally, our analysis of IPO operations confirms the significance of all factors considered in predicting the IPO trends in Europe, with a persisting accentuated impact generated by the market risk premium and the stock index STOXX Europe 600, also in this case. While previous analyses majorly focused on the US market, this paper is among first attempts to examine the topic of interest in the European context.
\end{abstract}

Keywords: risk premium, IPOs, leveraged buyouts, stock market

\section{Introduction}

Over the past twenty years, Leveraged Buyout (LBO) operations have followed a massive growth pattern in Europe, although the overall number of deals has varied significantly over time, moving from a maximum of 904 operations registered in the second semester of 2011 to a minimum of 147 operations registered in the first semester of 2015. In this paper we explore the underlying dynamics of such fluctuations. More specifically, we posit that the volume of buyout deals is affected by market risk premium variations, a thesis already put forward in the US market (Haddad, Loualiche, \& Plosser, 2017). In reality, the aforementioned notion comes in contrast with major literature in the field, which highlights market credit conditions as the key driver of buyouts.

The aim of this paper is to investigate the association between leveraged buyouts (LBOs), IPOs and market risk premium in the European market during the period spanning from the first quarter of 1999 to the fourth quarter of 2016. To our knowledge, this is the first work dealing with this topic in the European context. Furthermore, as shown in Figure 2 of Appendix A and thanks to the model applied in this analysis, we put forward the importance of an additional driver of LBO volumes - that is, the trend of the European stock index STOXX Europe 600, representative of 600 high capitalization firms operating in the European market.

Our work offers multiple contributions to existing research in the field of reference. Our primary contribution lies in the possibility we offer to define and depict a sound driver for buyout activity that can substantially alter the way corporate choices are shaped. From a managerial point of view, the latter would imply offering a concrete aid to all professional figures involved in the corporate decision-making processes in recognizing and determining the right timing regarding an acquisition, a key success factor in operations of the kind. What is more, we extend our analysis to include Initial Public Offering (IPO) operations in Europe during the same timeframe examined for buyouts. Findings suggest that the market risk premium is a crucial driver for both LBOs and IPOs (see Appendix A, Figure 3), despite the substantially different nature of the two.

The rest of the article is structured as follows: Section 2 presents an overview of the main literature on the topic of interest; Section 3 elaborates on the data and methodology employed in the analysis part of the study; Section 4 presents and discusses our empirical results, while we conclude with the practical implications of our work. 


\section{Literature Review and Hypotheses Development}

As anticipated, the relationship between market risk premium and LBO activity was initially examined in the US market (Haddad, Loualiche, \& Plosser, 2017), while other studies have examined the relationship focusing on market signals. In particular, credit market conditions have been found to affect financial leverage and price levels in buyout transactions (Axelson, Jenkinson, Strömberg, \& Weisbach, 2013). Furthermore, Kaplan and Strömberg (2009) indicate that errors in the determination of debt and equity values can generate positive effects in this typology of deal. More in general, the analysis carried out by Chiarella and Gatti (2015) emphasizes the importance of three main drivers as for the buyout activity volumes, namely: credit availability, economic growth and financial markets' optimism. From the aforementioned study it emerges that, despite a liquidity excess in the credit market, a contrast between the desire to invest and the need to avoid paying beyond what is due is generated. Based on these reasons, a future growth of buyout activity can be made possible only in the case that sees a stock market adjustment and future expectations improvement with regard to the overall economic trend.

Moving towards more specific analyses on LBOs, De Maeseneire and Brinkhuis (2012) suggest that financial leverage in this type of operations depends on the current conditions of the debt market. Elaborating such results, the authors observe that private equity firms tend to use increased financial leverage for a series of reasons, such as higher managerial discipline and benefitting from potential tax shields. With regard to the use of the market risk premium as a main driver of buyouts, no systematic analysis is available so far. Kaplan and Strömberg (2009) detail the function and mechanisms underlying private equity activity, but do not provide an exhaustive explanation on the reasons behind recurring buyout cycles. Martos Vila, Rhodes-Kropf and Harford (2012), on the other hand, offer an analysis on the distinction between financial acquisitions, where the main actors are private equity firms, and strategic acquisitions, where buyers are companies operating in the target firm's market. Their research focuses on the impact that wrong debt valuation has on the M\&A activity per se rather than on price or interest rate variations. Finally, Malenko and Malenko (2015) analyse the ability of companies managed by private equity (PE) to borrow capital independently of the reputation of their own financial sponsor - in this case the PE.

On another aspect of analysis, there is a series of academic works that look into important periods linked to specific events that strongly affected buyout activity. For instance, Shivdasani and Wang (2011) analyse the LBO boom that took place during the period 2004-2007, largely affected by the increase in Collateralized Debt Obligations (CDO) and other forms of securitization. Their analysis leads to the conclusion that the advent of such structured credit instruments made it possible to increase capital injected into LBO operations.

What is more, Kaplan and Stein (1993) examine 124 important LBO transactions, highlighting all the changes that occurred in terms of capital structure, expected returns and deal characteristics. Their thesis mainly implies the link between discount rates and corporate decisions. Moreover, stock market price variations are shown to affect the growth rate of investments in the US market by Barro (1990). Similarly, Cochrane (1991) links the returns in stock markets to those on investments. Berk, Green and Naik (1999) describe, instead, how firms make optimal investment choices through a dynamic model based on expected rates of return. Lastly, a study conducted by Cochrane (2011) demonstrates how discount rates affect not only the cost of capital but also the remuneration and capital structure of companies.

Concluding, the research hypothesis we test in this paper is the following: An increase of market risk premium in period $t$ leads to a decrease in LBO activity in period $t$.

\section{Data and Methodology}

Based on the conclusions reached and methodologies used in previous research, we study the relationship between LBO activity and the market risk premium running a log-linear regression model shaped as follows:

$$
\text { Lvalue }=\beta 1+\beta 2 \text { (mrp) }+\beta 3 \text { (bond) }+\beta 4(\text { STOXX600) }+\beta 5(\mathrm{GDP})+\mathrm{e}
$$

Consistently with previous literature, our dependent variable (Lvalue) represents the value of LBO deals expressed in $€$ million; represents MRP measures market risk premium in the European stock market; variable bond represents the iBoxx Euro Corporates index prices; STOXX600 represents the stock index STOXX600 prices; GDP represents the Gross Domestic Product at a European level. All data regarding our independent variables are drawn from the Thomson Reuters Datastream database and organized in historical series upon quarterly measurement.

At this point, it is necessary to specify the rationale behind our choice to transform the dependent variable into a logarithm. Such a decision is based - coherently with previous literature - on the fact that the relative 
observations follow an asymmetric pattern, characterized by right skewness. To account for such issue, Haddad, Loualiche and Plosser (2017) confirm the benefits of turning the key variable into a logarithm which allows harmonizing the statistical distribution of the data. In addition, the always positive values of the dependent variables in this model make choosing a log-linear model feasible.

Detailing our independent variables, definitions provided through academic literature regarding the market risk premium are manifold, as also outlined by Fernandez (2006). The concept of risk premium can, in fact, be broken down into four variants:

- Historical risk premium: historical differential between stock market returns and returns on the reference risk-free securities;

- Expected risk premium: expected differential between stock market returns and returns on the reference risk-free securities;

- Required risk premium: overall extra return that the stock market requires, compared to the returns associated with risk-free securities of reference, to compensate for the higher risk borne by investors;

- Implicit risk premium: coincides with the equity premium if we assume that markets are efficient and their pricing is correct.

While the historical market risk premium is the same for all investor categories, the expected, required and implicit risk premia vary according to the investor. In this study, we adopt the historical market risk premium, as calculated by Datastream's Absolute Strategy, and later form a composite index, grouping nine calculation models of the market risk premium that fall under the following three categories (Duarte \& Rosa, 2015):

- Dividend discount models: Gordon growth model, Damodaran DY and Adjusted Damodaran;

- Earnings driven models: Fed model of the return gap, gain return gap trend and 10- year gain return gap trend;

- Residual income models: residual income, 1-stage DCF and 3-stage DCF.

In order to put together all estimations deriving from the various models, we use the more reliable median, after observing the behaviour of different estimations in the time period considered (especially during 2000, the peak of the Dot-com bubble, and 2008 with the outbreak of the financial crisis). For the specific calculation of the European market risk premium, provided that the Eurozone does not have a de facto central government, we apply a 50:50 Germany-France combination of rates.

Our second independent variable (STOXX600 index) is employed to measure optimism levels present in the European stock market, one of the main drivers of buyouts, as indicated by Chiarella and Gatti (2015). The third variable (iBoxx Euro Corporates index), which is planned, calculated and constantly updated by Markit Ltd, is employed as a proxy for credit availability in the European zone. Credit availability affects, in its turn, two performance aspects for buyout deals: financial costs and equity contribution (Chiarella \& Gatti, 2015). With regard to the calculation method of the iBoxx Euro Corporates, the pricing process consists of the following steps:

- Real time listing;

- Quality check at an individual and comparative level;

- Pricing approval;

- Price consolidation;

- Price distribution for calculating the same index.

This procedure essentially aims at offering a transparent and easily functioning pricing service, which can be used by all professional players rather than merely by financial markets.

As for GDP, for the sake of coherence, we consider the Eurozone as the group of 28 countries of the European Union. For the years preceding the single currency, data are expressed in national currency and then converted in euros upon the definitive fixed currency rate.

Our final sample includes all deals concluded within the period that starts in the first quarter of 1999 and ends in the last quarter of 2016, as registered by the Zephyr database under the keywords: "acquisitions", Management Buy-out ("MBO") and Management Buy-In ("MBI"). We choose our timeframe of analysis based on the longest recent period with available data.

The same method, as presented so far, is applied regarding IPO activity in the European market. The base 
log-linear regression model is adopted adjusting for the dependent variable that, in this case, represents the natural logarithm of overall IPO deal values. The logarithmic model choice is made based on the same rationale previously discussed and our second model is shaped as follows:

\section{Results and Discussion}

$$
\ln I \mathrm{PO}=\beta 1+\beta 2(\mathrm{mrp})+\beta 3(\text { bond })+\beta 4(\mathrm{STOXX600)}+\beta 5(\mathrm{GDP})+\mathrm{e}
$$

\subsection{Leveraged Buyouts}

Table 1 summarizes key statistics for the model's variables. A total of 72 observations are available for each variable of the regression model, which coincide with the quarters corresponding to the period examined (1999 2016). The mean value of buyout deals is 212 billion euros, characterized by a high standlard deviation. The high value of buyouts comes in line with the peak of stock prices, confirming the strong relationship between the two.

Table 1. Summary statistics of analysis variables

\begin{tabular}{r|rrrrr} 
Variable & Obs & Mean & Std. Dev. & Min & Max \\
\hline value & 72 & 212720.4 & 137275.7 & 68188 & 912421 \\
mrp & 72 & .0442875 & .0162021 & .015 & .0773 \\
bond & 72 & 94.17418 & 4.38094 & 80.609 & 102.205 \\
stoxx600 & 72 & 295.3295 & 58.4991 & 176.415 & 397.298 \\
gdp & 72 & .0080069 & .0348813 & -.094 & .0626
\end{tabular}

With regard to market risk premium, we can observe a mean value of 4.4 per cent, as well as an inverse relationship with total buyout operations. Such finding may be explained considering that, in a positive market period, the risk borne by investors to hold financial assets is logically lower compared to that present in a negative phase of the markets.

Table 2. Statistical data on key dependent variable "Value"

$$
\text { value }
$$

\begin{tabular}{rrrlr}
\hline & Percentiles & Smallest & & \\
$1 \%$ & 68188 & 68188 & & \\
$5 \%$ & 78320 & 73668 & & \\
$10 \%$ & 97460 & 73888 & Obs & 72 \\
$25 \%$ & 123299 & 78320 & Sum of Wgt. & \\
& & & & \\
$50 \%$ & 171294 & & Mean & 12720.4 \\
$75 \%$ & 253609.5 & 482516 & Std. Dev. & 137275.7 \\
$90 \%$ & 382947 & 493542 & Variance & $1.88 \mathrm{e}+10$ \\
$95 \%$ & 482516 & 494993 & Skewness & 2.286779 \\
$99 \%$ & 912421 & 912421 & Kurtosis & 10.88882
\end{tabular}


Table 3. Statistical data on logarithmic version of key dependent variable "Lvalue"

\begin{tabular}{rrrll}
\multicolumn{5}{c}{ lvalue } \\
\hline & Percentiles & Smallest & & \\
$1 \%$ & 11.13002 & 11.13002 & & \\
$5 \%$ & 11.26856 & 11.20732 & Obs & 72 \\
$10 \%$ & 11.4872 & 11.21031 & Sum of Wgt. & 72 \\
$25 \%$ & 11.72237 & 11.26856 & Mean & 12.11101 \\
& & & Std. Dev. & .5443961 \\
$50 \%$ & 12.05105 & Largest & & \\
& & 13.08677 & Variance & .2963671 \\
$75 \%$ & 12.44355 & 13.10936 & Skewness & .44239 \\
$90 \%$ & 12.85565 & 13.1123 & Kurtosis & 2.777805 \\
$95 \%$ & 13.08677 & 13.72386 & &
\end{tabular}

Table 2 reports more detailed statistical information on the dependent variable. As previously mentioned, we can notice an asymmetric distribution, with marked right skewness. Similarly, Table 3 reports the same statistical information for the logarithmic version of the variable, helping one observe how the previous marked asymmetry is substantially reduced. Indeed, median and mean values for this variable are virtually identical. Regarding the choice of the specific functional form of the statistical model, we outline the two main guidelines:

- Opting for a functional form coherent with economic theory;

- Choosing a functional form flexible and easily adaptable to data available.

To point out the goodness of fit for our data adjustment, we include the residual distribution in a histogram as seen in Figure 1. As suggested by the residual distribution of the log-linear model, a normal statistical distribution present for our data supports our adjustments. An additional control is carried out with the residual distribution scatter diagram (Figure 2), which analyses the potential presence of recurrent patterns. The scatter diagram demonstrates the lack of specific trends. Before moving into the empirical results of this paper, Table 4 presents the Pearson correlation matrix for variables considered in the analysis. On this note, a negative correlation between MRP and lvalue is outlined, followed by a strong positive correlation between stoxx600 and value.

Table 4. Correlation matrix

\begin{tabular}{r|rrrrr} 
& lvalue & mrp & bond stoxx600 & gdp \\
\hline lvalue & 1.0000 & & & & \\
mrp & -0.4852 & 1.0000 & & & \\
bond & 0.1813 & -0.1633 & 1.0000 & & \\
stoxx600 & 0.7782 & -0.3428 & 0.1861 & 1.0000 & \\
gdp & 0.0560 & -0.1085 & 0.1037 & 0.1445 & 1.0000
\end{tabular}




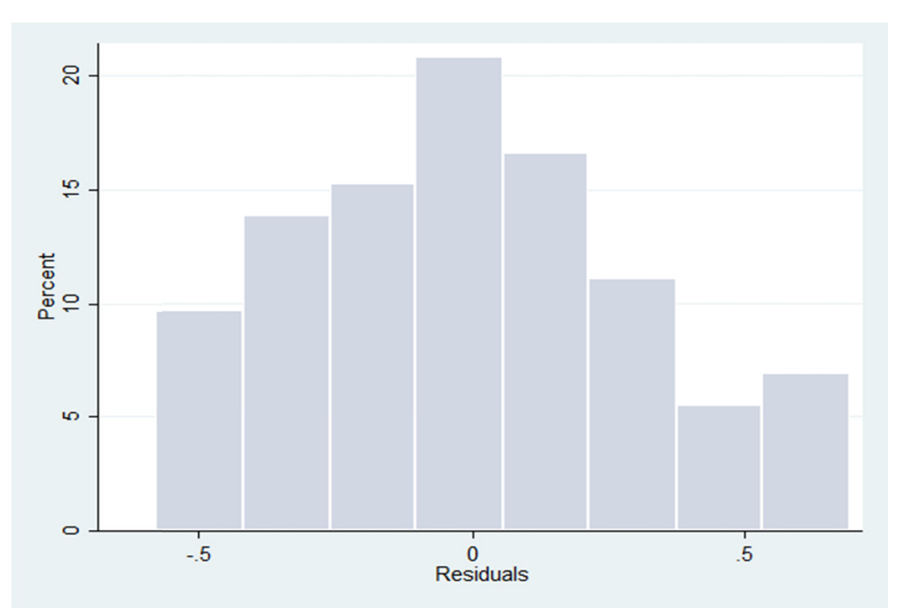

Figure 1. Residual distribution for the buyout model

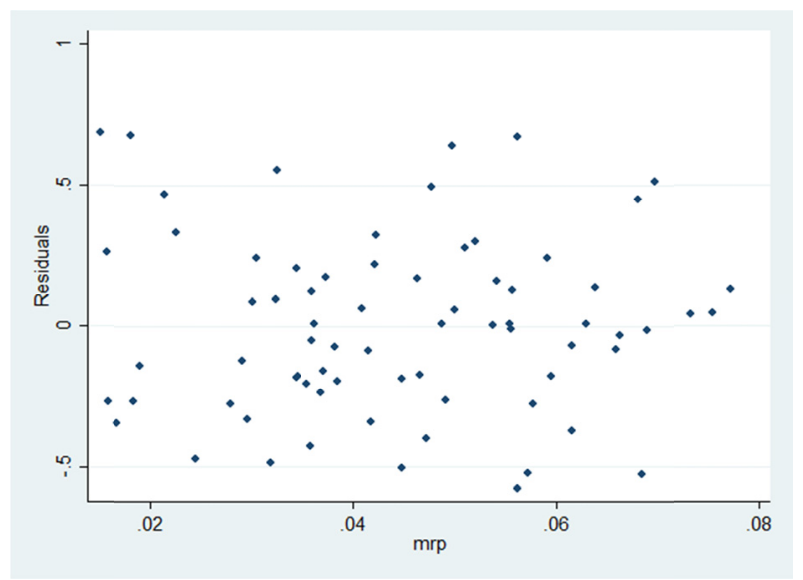

Figure 2. Scatter diagram of residual distribution for Buyout model

At this point, Table 5 reports the empirical findings regarding the relationship between buyout operations and market risk premium.

Table 5. Log-linear regression model outcome - Buyout activity

\begin{tabular}{|c|c|c|c|c|c|c|c|c|c|}
\hline $\begin{array}{l}\text { Independent } \\
\text { Variables }\end{array}$ & (1) & (2) & (3) & (4) & (5) & (6) & (7) & (8) & (9) \\
\hline MRP & $\begin{array}{l}-16.30 * * * \\
(3.606)\end{array}$ & & $\begin{array}{l}-15.73 * * * \\
(3.793)\end{array}$ & & $\begin{array}{l}-8.318^{* * *} \\
(2.699)\end{array}$ & & $\begin{array}{l}-16.29 * * * \\
(3.715)\end{array}$ & & $\begin{array}{l}-8.417 * * * \\
(2.811)\end{array}$ \\
\hline Bond & & $\begin{array}{l}0.0225^{*} \\
(0.0130)\end{array}$ & $\begin{array}{l}0.0130 \\
(0.0119)\end{array}$ & & & & & $\begin{array}{l}0.00530 \\
(0.00887)\end{array}$ & $\begin{array}{l}0.00222 \\
(0.00904)\end{array}$ \\
\hline Stoxx 600 & & & & $\begin{array}{l}0.00724 * * * \\
(0.000705)\end{array}$ & $\begin{array}{l}0.00645^{* * *} \\
(0.000671)\end{array}$ & & & $\begin{array}{l}0.00725^{* * *} \\
(0.000750)\end{array}$ & $\begin{array}{l}0.00651 * * * \\
(0.000684)\end{array}$ \\
\hline GDP & & & & & & $\begin{array}{l}0.873 \\
(1.742)\end{array}$ & $\begin{array}{l}0.0524 \\
(1.446)\end{array}$ & $\begin{array}{l}-0.952 \\
(1.200)\end{array}$ & $\begin{array}{l}-1.157 \\
(1.101)\end{array}$ \\
\hline Constant & $\begin{array}{l}12.83 * * * \\
(0.172)\end{array}$ & $\begin{array}{l}9.989 * * * \\
(1.237)\end{array}$ & $\begin{array}{l}11.58 * * * \\
(1.212)\end{array}$ & $\begin{array}{l}9.972 * * * \\
(0.204)\end{array}$ & $\begin{array}{l}10.57 * * * \\
(0.259)\end{array}$ & $\begin{array}{l}12.10^{* * *} \\
(0.0675)\end{array}$ & $\begin{array}{l}12.83 * * * \\
(0.180)\end{array}$ & $\begin{array}{l}9.479 * * * \\
(0.833)\end{array}$ & $\begin{array}{l}10.36 * * * \\
(0.936)\end{array}$ \\
\hline Observations & 72 & 72 & 72 & 72 & 72 & 72 & 72 & 72 & 72 \\
\hline $\mathrm{R}^{2}$ & 0.235 & 0.033 & 0.246 & 0.606 & 0.660 & 0.003 & 0.235 & 0.611 & 0.665 \\
\hline
\end{tabular}

Robust standard error are reported in brackets.

Levels of statistical significance: $* * * \mathrm{p}<0.01, * * \mathrm{p}<0.05, * \mathrm{p}<0.1$. 
We can observe that the variable MRP by itself is able to explain 23.5 per cent of variation in the dependent variable lvalue (column 1), while stoxx600 reports an r-squared level of 60.6 per cent, confirming the same trend present in the US market (Haddad, Loualiche, \& Plosser, 2017). The log-linear regression model further indicates an inverse relationship between the variable MRP and lvalue, supporting the thesis of the existence of a negative correlation between buyout activity volume and the market risk premium. Opposite, we witness a positive relationship between the STOXX600 index movements, capturing market optimism, and levels of buyout operations.

Our findings, therefore, offer support for our first hypothesis. Ultimately, we analyse the complete regression outcome, as presented in column 9 of Table 5:

$$
\text { Lvalue }=10,36-8,417(\operatorname{mrp})+0,002(\text { bond })+0,007(\text { stoxx } 600)-1,16(g d p)
$$

With regard to the analysis concerning the aggregate buyout deal volume concluded in Europe between 1999 and 2016, we can state that the key drivers are essentially two: the European market risk premium (MRP); the European market optimism levels (stoxx600). Quantitative support for this conclusion comes from significance levels at $1 \%$ and a remarkable r-squared indicator. Contrariwise, the variables bond and gdp do not result significant in our analysis. The latter may be attributed to a series of factors. One potential explanation regarding findings on the variable bond, may lie in the fact that the iBoxx Euro Corporates index used, which reports the interest rates of bonds issued by high rating firms that are prevalently investment grade securities, is too specific and does not represent in a comprehensive manner the trend and conditions of the credit market in the European area. Secondly, a measure such as the Gross Domestic Product potentially fails to represent the economic growth of a complex and heterogeneous conglomerate of countries such as the European one.

\subsection{IPOs}

We extend our analysis to further examine the relationship between market risk premium and an additional type of extraordinary financial operation: IPOs. The mean value of these operations is 9.7 billion euros, with a range from a minimum of 65 billion (third quarter of 2002) to a maximum of 40.7 billion euros (fourth quarter of 1999). Tables 6 and 7 report statistical information on the dependent variable.

Table 6. Statistical data for dependent variable "IPO"

\begin{tabular}{rrrlr}
\multicolumn{5}{c}{ IPO } \\
\hline & Percentiles & Smallest & & \\
18 & 65 & 65 & & \\
$5 \%$ & 312 & 70 & Obs & 72 \\
$10 \frac{8}{8}$ & 862 & 196 & Sum of Wgt. & 72 \\
$25 \%$ & 2691.5 & 312 & & \\
& & & Mean & 9783.917 \\
508 & 7222 & Largest & Std. Dev. & 9395.416 \\
& & 30250 & & \\
$75 \%$ & 13108.5 & 35376 & Variance & $8.83 \mathrm{e}+07$ \\
908 & 23412 & 36842 & Skewness & 1.429936 \\
$95 \frac{8}{8}$ & 30250 & 40748 & Kurtosis & 4.549591 \\
998 & 40748 & & &
\end{tabular}

Table 7. Statistical data for logarithmic version of variable "IPO"

\begin{tabular}{|c|c|c|c|c|}
\hline \multicolumn{5}{|c|}{ InIPo } \\
\hline & Percentiles & Smallest & & \\
\hline 18 & 4.174387 & 4.174387 & & \\
\hline $5 \frac{8}{8}$ & 5.743003 & 4.248495 & & \\
\hline $10 \%$ & 6.759255 & 5.278115 & Obs & 72 \\
\hline $25 \%$ & 7.89633 & 5.743003 & Sum of Wgt. & 72 \\
\hline $50 \%$ & 8.884883 & & Mean & 8.597083 \\
\hline & & Largest & Std. Dev. & 1.348377 \\
\hline $75 \%$ & 9.479749 & 10.31725 & & \\
\hline $90 \%$ & 10.061 & 10.47379 & Variance & 1.818121 \\
\hline $95 \%$ & 10.31725 & 10.51439 & Skewness & -1.224336 \\
\hline 998 & 10.61516 & 10.61516 & Kurtosis & 4.803592 \\
\hline
\end{tabular}


We notice that the mean of 9.78 billion euros is much larger than the median of 7.2 billion euros, indicating an asymmetry in the distribution with a right skewness. To adjust such asymmetry we convert the dependent variable IPO into its logarithmic version, (lnIPO). Also in this case, Figures 3 and 4 elaborate the goodness of data adjustment.

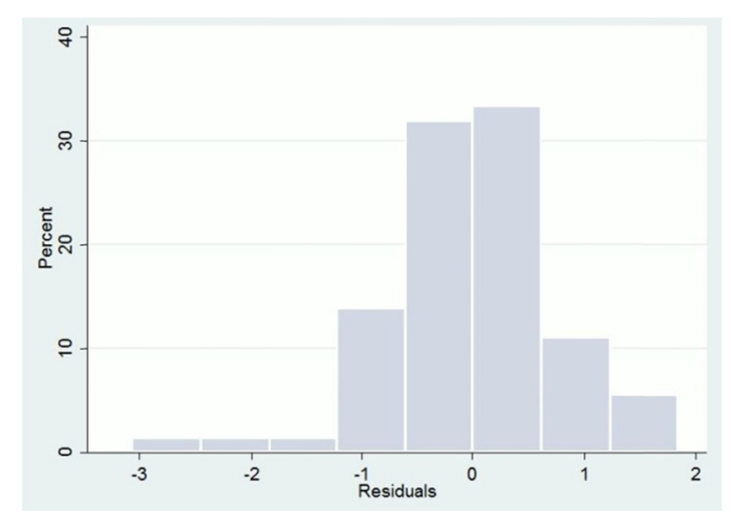

Figure 6. Residual distribution for IPO model

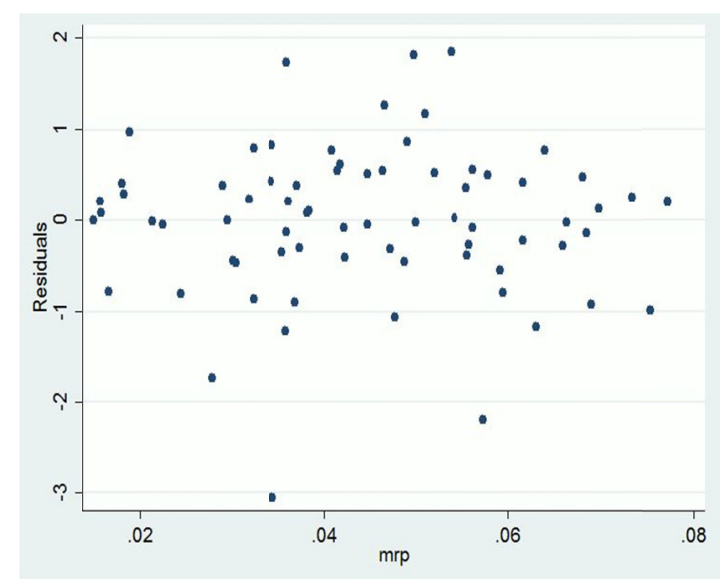

Figure 7. Scatter diagram for IPO model

Following, Table 8 presents the empirical findings regarding the relationship between IPO activity and the market risk premium.

Table 8. Model outcome for IPO

\begin{tabular}{|c|c|c|c|c|c|c|c|c|c|}
\hline $\begin{array}{l}\text { Independent } \\
\text { Variables }\end{array}$ & (1) & (2) & (3) & (4) & (5) & (6) & (7) & (8) & (9) \\
\hline MRP & $\begin{array}{l}-35.04 * * * \\
(8.958)\end{array}$ & & $\begin{array}{l}-41.52 * * * \\
(7.476)\end{array}$ & & $\begin{array}{l}-15.89 * * * \\
(6.487)\end{array}$ & & $\begin{array}{l}-33.09 * * * \\
(8.199)\end{array}$ & & $\begin{array}{l}-13.62 * * * \\
(6.043)\end{array}$ \\
\hline Bond & & $\begin{array}{l}0.0987 * * * \\
(0.0415)\end{array}$ & $\begin{array}{l}0.0797 * * * \\
(0.0336)\end{array}$ & & & & & $\begin{array}{l}0.0551 * * * \\
(0.0255)\end{array}$ & $\begin{array}{l}0.0501 * * \\
(0.0236)\end{array}$ \\
\hline Stoxx 600 & & & & $\begin{array}{l}0.0170 * * * \\
(0.00220)\end{array}$ & $\begin{array}{l}0.0155 * * * \\
(0.00230)\end{array}$ & & & $\begin{array}{l}0.0157 * * * \\
(0.00193)\end{array}$ & $\begin{array}{l}0.0145^{* * *} \\
(0.00220)\end{array}$ \\
\hline GDP & & & & & & $\begin{array}{l}10.02 * \\
(5.314)\end{array}$ & $\begin{array}{l}8.354 * \\
(4.387)\end{array}$ & $\begin{array}{l}5.489 * \\
(2.797)\end{array}$ & $\begin{array}{l}5.157^{*} \\
(2.646)\end{array}$ \\
\hline Constant & $\begin{array}{l}10.15^{* * * *} \\
(0.391)\end{array}$ & $\begin{array}{l}-0.700 \\
(3.971)\end{array}$ & $\begin{array}{l}2.489 \\
(3.181)\end{array}$ & $\begin{array}{l}3.581 * * * \\
(0.709)\end{array}$ & $\begin{array}{l}4.730 * * * \\
(0.894)\end{array}$ & $\begin{array}{l}8.517 * * * \\
(0.169)\end{array}$ & $\begin{array}{l}9.996 * * * \\
(0.366)\end{array}$ & $\begin{array}{l}-1.281 \\
(2.462)\end{array}$ & $\begin{array}{l}0.146 \\
(2.327)\end{array}$ \\
\hline Observations & 72 & 72 & 72 & 72 & 72 & 72 & 72 & 72 & 72 \\
\hline $\mathrm{R}^{2}$ & 0.177 & 0.103 & 0.242 & 0.543 & 0.575 & 0.067 & 0.223 & 0.598 & 0.621 \\
\hline
\end{tabular}

Robust standard error in brackets. $* * * \mathrm{p}<0.01, * * \mathrm{p}<0.05, * \mathrm{p}<0.1$. 
In this model, all independent variables result significant in their explanatory power over the variability of IPO deal volumes. It should be noted, also in this case, that the variable STOXX600 is the most significant driver of activity. The market risk premium reports, in the mean time, a positive r-squared value (17.7 per cent, column 1), resulting the second most significant component of the model. As for the overall relationships between the independent variables and the dependent variable lnIPO, we report the Pearson correlation index matrix in Table 9 .

Table 9. Correlation matrix for IPO model

\begin{tabular}{r|rrrrr} 
& InIPO & $\mathrm{mrp}$ & bond stoxx600 & gdp \\
\hline InIPO & 1.0000 & & & & \\
mrp & -0.4210 & 1.0000 & & & \\
bond & 0.3207 & -0.1633 & 1.0000 & & \\
stoxx600 & 0.7369 & -0.3428 & 0.1861 & 1.0000 & \\
gdp & 0.2592 & -0.1085 & 0.1037 & 0.1445 & 1.0000
\end{tabular}

The correlation matrix confirms the negative correlation between MRP and InIPO and the positive correlation between $\operatorname{lnIPO}$ and all the dependent variables bond, stoxx600 and gdp.

The last phase of the analysis concerning IPO volumes in Europe considers the extended version of the base model as seen in column 9 of the empirical findings Table 8:

$$
\operatorname{lnIPO}=0,146-13,62(\mathrm{mrp})+0,0501(\text { bond })+0,0145(\text { stoxx } 600)+5,157(\mathrm{gdp})
$$

Based on our findings, when the STOXX Europe 600 index price increases by one unit, the InIPO variable increases by 1.5 per cent, while, as for the market risk premium, the variation of one per cent corresponds to a drop of $\operatorname{lnIPO}$ by 13.62 per cent.

It is possible to conclude that all drivers considered are valid. Differently from the previous analysis concerning buyouts, in fact, in this case all independent variables present high significance levels. It is, however, important to outline that the strongest driver is still to be found in the stock market index STOXX Europe 600, together with the market risk premium. Furthermore, we confirm the inverse relationship between the market risk premium and the levels of IPO activity. This finding is particularly interesting because it can explain the dynamics behind recurrent IPO booms in financial markets, not only at a European but also at a global level. On the other hand, the strongly positive and significant link between the index movements and the IPO activity highlights the importance of the stock trend in evaluating the historical waves of stock exchange listings.

\section{Managerial and Theoretical Implications}

To assess the impact of findings in this paper from a managerial point of view, we must outline the context in which we are moving: LBOs and IPOs. These two types of operations have one crucial element in common: they are both extraordinary financial transactions that have a substantial effect on the structure of the firms involved. By taking into account buyouts, it is fortuitous to keep in mind the main elements distinguishing the ideal acquisition target (Rosenbaum e Pearl, 2013):

- Strong ability to generate cash flows;

- Good market position;

- Growth opportunity;

- Efficiency improvement potential;

- Low CAPEX requirements;

- Sound total assets.

Based on our findings, we can further conclude that when the market risk premium decreases the level of LBOs in the market rises and vice versa. Therefore, the identified drivers represent an important element to bear in consideration when outlining corporate strategy and defining investment decisions. With such regard, a long series of market players are to be affected by such considerations, including firms involved in acquisition transactions, financial sponsors, investment banks, institutional banks and financiers, bond investors, corporate managers. Each of these market actors has an interest to be able to identify market momentum and benefit from 
favourable conditions, especially when this type of scale of operations is involved.

We, thus, suggest two series of conditions to be accounted for before proceeding with an LBO: conditions concerning the operation itself (characteristics of the target firm and modality of financing used) and general market conditions. In the first case, it is vital to individually examine the previously listed elements. The second point, instead, strictly concerns the focus of this research paper and it involves verifying the market condition both regarding the climate in stock markets and the premium required by them. If both external and internal conditions are favourable, there is an increased probability of success.

Our paper makes it clear that when a company wishes to proceed with an LBO it must first analyze its target and understand whether market dynamics - that is external conditions - are favourable, other than analysing the intrinsic reasons behind this operation. A proper framework should, therefore, include the following steps:

- Express the corporate strategy

- Define the objective of the acquisition

- In case of buyout, define the structure of the deal

- Identify the ideal target

- Comprehend the market situation.

Furthermore, our findings offer a new intuition on the direct relationship between both types of operation volumes and the stock index STOXX Europe 600, with the latter confirmed as an important explanatory factor of LBO trends. Another interesting highlight lies in the lack of evidence on a relationship between buyouts and the national gross domestic product, as well as the credit market condition.

Moreover, we extend our assumptions on buyouts to IPO activity as well. We can state how, in this case, each factor considered results significant. Regarding IPOs, they present an inverse relationship with market risk premium and a positive one with the stock market index, bond prices and aggregate GDP. This set of variables, therefore, represents a number of factors to be considered when examining the ideal market conditions to be listed on the stock exchange (Bancel \& Mittoo, 2009).

\section{Conclusions}

This paper aimed at investigating the relationship between leveraged buyouts (LBOs), IPOs and market risk premium in the European market. Accordingly, we have proceeded with an analysis that considers the European context during an extensive period of time that spans from 1999 to 2016. The model implemented has produced results in line with our hypothesis; i.e. an inverse correlation between the market risk premium and the volume of buyouts is documented in the European market. Additionally, a direct relationship between operation volumes and market optimism is documented. Both relationships also confirmed for IPO operations.

Concluding, we recognize the limitations that characterize our examination. With respect to buyout activity, one should put into consideration the use of debt that more often than not is fundamental in this kind of operations. The variable bond included in our statistical model, however, does not show an acceptable significance level, and this is an issue that should be further explored. It is possible that in the European context, differently to US market this kind of factor is less influential compared to other variables such as the market risk premium or the European stock index. Another potential explanation may lie in the fact that in Europe, given the differences between different countries, it is difficult to identify credit conditions simply employing a unique index. A third possible explanation may be found in the fact that in order to capture a correlation between required returns for debt capital and buyout activity, it may be necessary to extrapolate the interest rate of high yield bonds. The latter is due to the tangible complexity present in this kind of financial operations that leads to an increased risk sustained by investors in leveraged deals.

Prospects opened by this paper are wide; once verified the efficacy of the statistical model for buyouts and IPOs in Europe, it would be interesting to understand if such relationship is present in other high developing foreign markets, such as the Asian financial markets. Moreover, this model can be tested for other M\&A operations (mergers, acquisitions, spin-offs, carve-outs), trying to also point out the importance of regulation in financial markets and its incisiveness.

With the market risk premium as a sound driver of buyout and IPO activity, actors in the market need to realize that market conditions are fundamental in determining an upcoming - or less -wave. If the required return from market is in fact too high, it will be less convenient to finance this kind of operations. The key element to remember is that these instances of decision-making determine the deliberate strategy pursued by management, and consequentially the strategy applied on potential acquisitions. It is, in other words, legitimate to infer that 
market conditions are a determining factor of strategy goals, even though the latter may and should be modified through efficient feedback processes concerning the competitive background. The instrument proposed in this work, finally, can turn into a practical analytical tool, not only useful to corporate management, but also to a variety of market players in their pursuit to render financial markets more transparent and consequentially more efficient.

\section{References}

Axelson, U., Jenkinson, T., Strömberg, P., \& Weisbach, M. S. (2013). Borrow cheap, buy high? The determinants of leverage and pricing in buyouts. Journal of Finance, 68, 2223-2267 https://doi.org/10.1111/jofi.12082

Bancel, F. and Mittoo, U. R. (2009). Why do European firms go public? European Financial Management, 15(4), 844-884. https://doi.org/10.1111/j.1468-036X.2009.00501.x

Barro, R. J. (1990). The stock market and investment. Review of Financial Studies, 3, 115-131.

Berk, J.B., Green, R.C. and Naik, V. (1999). Optimal Investment, Growth Options, and Security Returns. Journal of Finance, 54(5): 1553-1607. https://doi.org/10.1111/0022-1082.00161

Chiarella, C., \& Gatti, S. (2015). Private Equity Investments - Financial markets, macroeconomic trends and the return of leveraged buyouts. Position paper. Baffi Carefin, Bocconi University.

Cochrane, J. H. (1991). Production-based asset pricing and the link between stock returns and economic fluctuations. Journal of Finance, 46, 209-237.

Cochrane, J. H. (2011). Presidential address: discount rates. Journal of Finance, 66, 1047-1108. https://doi.org/10.1111/j.1540-6261.1991.tb03750.x

De Maeseneire, W., \& Brinkhuis, S. (2012). What drives leverage in leveraged buyouts? An analysis of European leveraged buyouts' capital structure. Accounting and Finance, 52, 155-182. https://doi.org/10.1111/j.1467-629X.2011.00431.x

Duarte, F., \& Rosa, C. (2015). The equity risk premium: a review of models. Federal Reserve Bank of New York. Staff Report no.714, 02/2015.

Fernández, P. (2006). Equity premium: historical, expected, required and implied. Working paper. IESE Business School-University of Navarra.

Haddad, V., Loualiche, E. and Plosser, M. (2017). Buyout activity: the impact of aggregate discount rates. Journal of Finance, 72, 371-414. https://doi.org/10.1111/jofi.12464

Kaplan, S. N., \& Stein, J. C. (1993). The evolution of buyout pricing and financial structure in the 1980s. Quarterly Journal of Economics, 108, 313-357.

Kaplan, S. N., \& Strömberg, P. (2009). Leveraged buyouts and private equity. Journal of Economic Perspectives 23, 121-146. http://dx.doi.org/10.1257/jep.23.1.121

Malenko, A., \& Malenko, N. (2015). A theory of LBO activity based on repeated debt-equity conflicts. Journal of Financial Economics, 117, 607-627. http://dx.doi.org/10.2139/ssrn.2251169

Martos-Vila, M., Rhodes-Kropf, M., \& Harford, J. (2012). Financial vs. strategic buyers. Working paper. Harvard Business School.

Rosenbaum, P. (2013). Investment Banking: Valuation, Leveraged Buyouts, and Mergers \& Acquisitions (2nd ed.).

Shivdasani, A., \& Wang, Y. (2011). Did structured credit fuel the LBO boom? Journal of Finance, 66, 1291-1328. https://doi.org/10.1111/j.1540-6261.2011.01667.x

\section{Copyrights}

Copyright for this article is retained by the author(s), with first publication rights granted to the journal.

This is an open-access article distributed under the terms and conditions of the Creative Commons Attribution license (http://creativecommons.org/licenses/by/4.0/). 